\title{
Situación del financiamiento al sector reformado Salvadoreño
}

\author{
José Paz
}

\section{Introducción}

Al iniciar esta exposición pienso que es adecuado citar la dedicatoria que aparece en el libro: "Undermining Rural Development with Cheap Credit", editado por Dale W. Adams, Douglas H. Graham y J. D. Von Pischke. Profesores de economía agrícola de la Universidad de Ohio los primeros y Analista Financiero de la Divisíon de Economía y Política del Departamento de Desarrollo Rural del Banco Mundial, el tercero.Ellos escribieron "Dedicamos este libro a los centenares de millones de campesinos pobres de los países de bajos ingresos que no obtienen crédito barato ni retornos adecuados a sus ahorros sin saber por qué; a los miles de empleados de bancos agricolas y cooperativas quienes dan lo mejor de sí a los programas de crédito que operan deficientemente, por razones que escapan a su control, y a los miles de responsables del diseño de políticas que tratan de ayudar al campesino pobre, pero que no pueden pensar en un modo mejor de hacerlo que a través del crédito barato". ${ }^{1}$ Espero que el mensaje contenido en el anterior párrafo ayude a asimilar lo que sigue.

En las últimas décadas, se han establecido miles de programas de crédito en los países de bajos ingresos, con el propósito de apoyar actividades específicas de desarrollo o de facilitar el acceso al financiamiento formal a grupos determinados tales como pequenos agricultores, microempresarios, beneficiarios de reformas agrarias, etc. En la mayoría de estos países se crearon instituciones financieras que invariablemente siguieron un patrón similar en sus operaciones. Las características comunes a este tipo de programas y patrones comunes de operar de las instituciones han sido sef́aladas por investigadores del comporatamiento de los mercados financieros (MFs). ${ }^{2}$

Uno de los objetivos del establecimiento de instituciones espe- 
cializadas fue el de facilitar el acceso al crédito formal a grupos seleccionados. En la práctica, éstas han aplicado invariablemente una política de discriminación contra aquellos clientes considerados de un alto riesgo por carecer de garantías adecuadas para respaldar sus préstamos. Aún más, como la mayoría de los programas sef́alados tienen fijadas tasas nominales de interés preferenciales, es decir generalmente más bajas que las tasas fijadas para otras actividades y negativas en términos reales ${ }^{3}$, se crea un exceso de demanda por el crédito a la tasa preferencial fijada. Ante la presencia del exceso de demanda, la asignación de los préstamos se efectúa mediante mecanismos que no responden necesariamente a los criterios de mercado. Se raciona el crédito mediante el establecimiento de cuotas o creación de procedimientos complejos de tramitación marginado del mercado sobre todo a prestatarios de pequenos montos. Asimismo, la asignación del crédito a través de criterios que no responden a los mecanismos de mercado distorcionan el funcionamiento de los MFs, empeora la ya mala distribución de ingresos, a través de una concentración del crédito en manos de pocos. ${ }^{4}$

Además de las tasas subsidiadas de interés, la mayoría de los programas de crédito establecidos en los países en vías de desarrollo sobreestiman lo que realmente pueden hacer el crédito. No hay duda de que el sistema financiero tenga un rol importante en el desarrollo económico. Pero, no se pueden remediar los males del subdesarrollo con solamente el crédito. Como indica el Doctor Claudio González-Vega, el crédito subsidiado no pone en el lugar una infraestructura faltante, tales como caminos, mercados, tecnología adecuada, etc. El crédito es sólo un instrumento financiero que da liquidez adicional al que lo obtiene. ${ }^{5}$ Otro aspecto que se olvida en el diseno de los programas de crédito es el hecho de que la tasa de interés no es el único costo, sino que los costos de transacción son factores determinantes en las decisiones de los participantes en el mercado financiero.

En esta exposición quiero aclarar primeramente conceptos básicos como son el de sistema de entrega de crédito y el de costo de transacción asociado. Luego, discutir las imperfecciones que surgen en el mercado en presencia de determinadas políticas. Seguidamente trataré de explicar la conducta de los participantes en el mercado financiero salvadoreno con énfasis en el mercado financiero para el sector agrario reformado. Finalmente presentaré algunas conclusiones para discusión en los grupos de trabajo de reunión plenaria del Seminario.

\section{Sistema de entrega de crédito y costos de transacción aso- clados}

Como ya senalé anteriormente, una de las características que se 
encuentran en los programas de crédito de los países en vías de desarrollo, es el énfasis en el costo financiero para los prestatarios y prestamistas. Sin embargo, en la práctica, tanto del punto de vista del prestamista como del punto de vista del prestatario, son importantes los costos en los que unos y otros incurren al tramitar el crédito unos y al conceder los préstamos los otros. Los costos totales son los que importan, es decir el costo financiero y los costos asociados a la tramitación, concesión de los préstamos, recuperación, mantenimiento de depósito y manejo de éstos.

\section{Sistema de entrega de crédito}

El Sistema de Entrega de Crédito (SDC) es el procedimiento establecido por una institución financiera para la tramitación y administración de un préstamo hasta su recuperación. Cada línea de crédito con sus condiciones y sus procedimientos de tramitación tienen su propio SDC. Las condiciones de los préstamos y mecanismos de tramitación aparentemente son iguales para una línea de crédito. Pero, el grado de dificultad o complejidad de un SDC puede ser mayor o menor dependiendo de quien tramita el préstamo. Para un campesino analfabeto y un empleado de un banco, el mismo SDC presenta grados de complejidad totalmente diferentes.

La documentación requerida, la clase de garantía exigida por los prestamistas, los plazos del préstamo, tasa de interés y la modalidad de desemboldo son parte del SDC. Asi también son parte del SDC los pasos y acciones que toman las instituciones financieras para conceder los préstamos. Por ejemplo, la información requerida debe ser analizada. En algunos casos, las instituciones financieras visitan las propiedades, hacen valúo de las garantías, etc. Estas acciones son también parte del SDC.

Existe una relación entre un préstamo y el costo de obtención para el prestatario. Al mismo tiempo, existe otro costo para el prestamista para la concesión de ese préstamo. Investigaciones recientes han probado suficientemente que los programas de crédito disefrados con tasas de interés preferenciales tienen también complejos SDC y costos de transacción comparativamente mayores. ${ }^{6}$

\section{Costos de Transacción}

Los prestatarios incurren en gastos desde el momento en que inician los trámites para cumplir con las condiciones exigidas por los prestamitas. Los costos de transacción son explícitos e implícitos. Son costos explicitos los gastos en efectivo tales como el pago por la obtención de documentos, gastos de pasajes, de alimentación, propinas, comisiones, etc. Son costos implícitos los costos tales como el tiempo transcurrido en 
la tramitación de documentos medido en términos de lo que deja de ganar una persona por dedicar su tiempo a esta actividad. Podrían considerarse también como costos implícitos los costos que resultaren de utilizar crédito informal por el desembolso tardío o por la concesión de fondos insuficientes que obligarían al prestatario a recurrir a préstamos informales.

Los costos de transacción del prestamista comienzan en el momento en que un cliente solicita un préstamo. Si se trata de un cliente nuevo, la institución necesita recabar información sobre el cliente potencial. El prestamista también requiere revisar la documentación presentada, analizar la solicitud, visitar y supervisar la finca o el lugar del proyecto y evaluar las garantías presentadas. Todo lo anterior consume tiempo y recursos que son costosos. Si la institución decide conceder el préstamo esta etapa tiene también sus propios elementos de costo. Cada cliente es un caso especial y merece una atención mayor o menor dependiendo de la importancia del préstamo. Los costos de transacción tanto del prestatario como del prestamista no necesariamente dependen del volumen del préstamo, es decir, tienen un compomente de costo fijo. En general los costos de administrar un préstamo son iguales para cualquier monto de préstamo. Otros costos tales como recabar información sobre los clientes pueden ser mayores o menores dependiendo de la clase de prestatario y del monto del préstamo.

Los factores que determinan la magnitud de los costos de transacción tanto del prestamista como del prestatario son probablemente múltiples y algunos de ellos son más importantes que otros. Se ha tratado de medir la correlación existente entre el costo de transacción del prestatario con variables tales como el tamaño del préstamo, distancia del domicilio del prestatario a la sucursal del banco, el grado de educación del prestatario, el tipo de garantía exigido, los plazos, tasas de interés nominales, el tiempo de relación del cliente con el banco. Las conclusiones a las que llegan esos estudios revelan hechos importantes que podrían tomar en consideración los disenadores de política crediticia. ${ }^{7}$

\section{Condiclones del mercado}

Los mercados financieros funcionan igual que otras mercados. Las instituciones financieras (IFs) formales e informales constituyen el lado de la oferta y los prestatarios y depositantes o ahorristas demandas los servicios. Las IFs producen servicios o productos financieros. Este proceso de producción tienen sus costos. Además de los costos financieros tienen, como se dijo antes, los de transacción. Como quiera que los recursos prestables tienen usos alternativos, existe un costo de oportunidad y además existe un cośto que está asociado a la tasa de recuperación de la cartera que depende de variables totalmente aleatorias. 
En los paises en vías de desarrollo el funcionamiento de los MFs está altamente controlado. En la mayoría de los casos no es un mercado competitivo si bien exiten algunos elementos que dan lugar a un tipo de competencia. Por ejemplo, la IFs, como demandantes de depósitos, pagan uniformemente una tasa pasiva igual a cada categoria de depósitos, compitiendo entre sí utilizando incentivos que no son directamente el precio. Sin embargo, como vendedores de sus productos actúan como oligopolios, monopolios de planta múltiple o monopolios con discriminación de precio.

Se han utilizado diversos tipos de modelos para el análisis del comportamiento de los MFs en los países de bajos ingresos. Sin embargo, un modelo que puede explicar y predecir lo que ocurre en esos mercados es el del monopolio de múltiple planta con discriminación de precio. La discriminación se da cuando un mismo producto o servicio se vende a más de un precio. Por ejemplo, si una determinada intervención quirúrgica se vende a $₫ 5,000$ a un rico y a $₫ 1,000$ a un pobre. Este tipo de discriminación se da en los MFs. De otro lado, es evidente que los prestamistas consideran los diferentes préstamos como productos no homogeneos, sino diferenciados por clases de prestatario. Este hecho hace que los préstamos pueden tratarse como productos diferenciados.

Los costos de producir cada tipo de préstamo son diferentes por el hecho de que las condiciones varian de contrato a contrato. Como se dijo antes, existe un elemento aleatorio inherente a las operaciones de las instituciones financieras sobre la recuperabilidad del préstamo. Este costo es mayor o menor dependiendo de los mismos prestatarios y del éxito o fracaso de las actividades a que se destinan los recursos obtenidos en el préstamo. Este conjunto de factores determina la conducta del prestamista.

En el lado de la demanda, los prestatarios compiten por tener acceso a un préstamo y cada uno de ellos tiene su propia curva de demada el cual muestra la cantidad de préstamo para un determinado precio, tasa de interés, y un costo de transacción. Si las tasas de interés son preferenciales, la demanda global excederá a la disponibilidad de fondos prestables.

\section{Conducta del prestamista}

Si el prestamista practica la discriminación debe responder a dos preguntas: Cuánto préstamo debe colocar a cada clase de prestatario y qué precio debe cargar a cada clase de préstamo. La respuesta lógica inmediata a la seguna pregunta sería que el precio deberá ser más bajo donde la elasticidad precio de la demanda es más elástica. Se supone que los prestatarios con mayores recursos y posición financiera más sólida tienen elasticidades precio de demanda menos elástica. 
La respuesta a la segunda preguna está relacionada con los objetivos que persigue el prestamista. Inicialmente voy a suponer que las IFs tienen el objetivo de maximar la diferencia entre sus ingresos y costos totales. Si este es el caso, ellas tratarán de colocar un monto total de préstamos hasta lograr que el costo marginal total iguale al valor de los ingresos marginales totales. Con la ayuda de un gráfico se explica cómo ocurre lo anterior. Por simplicidad se supone que existen solo dos clases de préstamos y que el monopolista (prestamista) incurre en costos diferentes y que también aplica los préstamos precios discriminados.

Figura 1. Caso de un prestamista con costos diferenciales y discriminación de precios

Tasa de interés efectiva

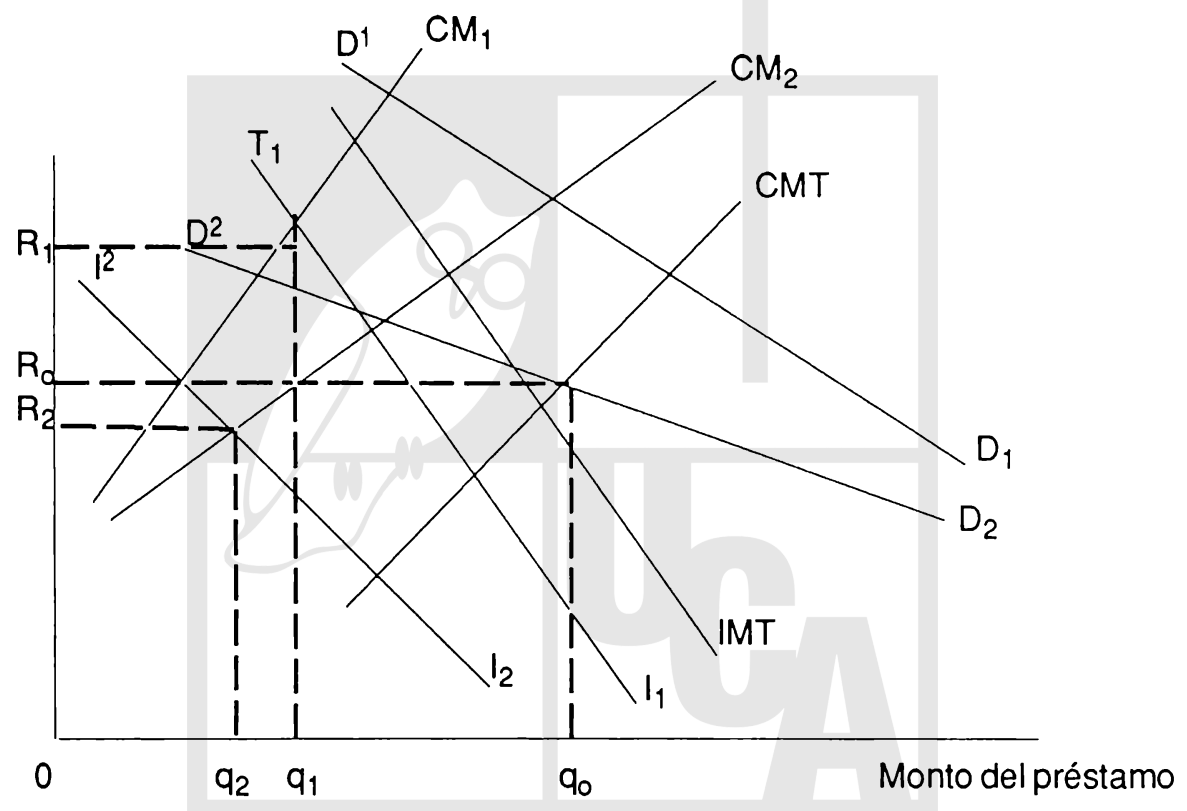

Como se muestra en la figura, $D_{1} D_{1}$ y $D_{2} D_{2}$ representan las curvas de demanda para las dos clases de préstamos 1 y $2, l_{1} l_{1}$ y $l_{2} l_{2}$ son las curvas de demanda anteriores. Los costos $\mathrm{CM}_{1}$ y $\mathrm{CM}_{2}$ representan los costos en que incurre el monopolista. Para optimizar las ganancias (ingresos menos costos totales), el monopolista deberá colocar un monto $\mathrm{Oq}_{0}$ de préstamo total entre las dos clases de préstamos. En ese punto el ingreso marginal total (IMT) es igual al costo marginal (CMT). De esta 
manera coloca a la primera clase de préstamos $O q_{1}$ unidades al precio $\mathrm{OR}_{1}, \mathrm{Oq}_{2}$ a la segunda, al precio $\mathrm{OR}_{2}$ y el precio promedio es $\mathrm{OR}_{\mathrm{o}}$. No significa esto que todas las instituciones financieras tienen como objetivo maximizar sus utilidades. Pero, parece razonable suponer que todas deben operar con cierto grado de eficiencia, pués de algún modo serán evaluadas bajo criterios de eficiencia económica. Además, en el largo plazo, sólo tendrá viabilidad financiera aquellas que por lo menos operen en un punto de equilibrio entre costos e ingresos.

\section{Conducta del prestatario}

El prestario tomará su decisión de cuánto préstamo solicitar a cada precio. El precio en que él basará su decisión incluye la tasa de interés y los demás costos. Estos serán comparados con la rentabilidad esperada de los fondos que obtendrá. Si la rentabilidad esperada de las actividades a que destinará los fondos superan los costos totales, entonces solicitará los fondos.

La demanda individual por préstamo se puede decir que es una función de la tasa de interés real, los costos de transacción y rentabilidad esperada de los usos a que se destinará el crédito. En el caso de que las tasas de interés sean negativas, la rentabilidad esperada aumenta y los individuos demandan montos superiores para utilizarlos en usos especulativos y hasta en consumo. De esta manera, cuando las tasas nominales se fijan sin tomar en cuenta la tasa de inflación, el exceso de demanda por crédito obliga a las intituciones financieras a seleccionar los clientes por mecanismos y criterios que no responden al mecanismo de mercado.

Para que la demanda del prestatario sea atendida, éste debe llenar las condiciones impuestas por la IF. El es libre de solicitar el monto de préstamo que considere razonable para la actividad a que destinará los fondos, pero la decisión final depen de la IF. En la práctica, puede recibir el monto solicitado, menor que el monto solicitado o simplemente la solicitud es negada. En el último caso, su alternativa sería acudir a otra institución financiera formal o informal. El resultado de que obtenga el préstamo depende en parte de él y en parte de factores que escapan a su control.

\section{Racionamiento de crédito}

Como los precios que rigen en los MFs formales de los países en vías de desarrollo están generalmente fijados, las asignaciones de préstamos no se discriminan a través del precio, sino más bien se utilizan mecanismos diferentes al precio. Estos mecanismos incluyen racionamiento a través de fijación de montos por hectárea cultivada, montos, de produc- 
ción anterior, o establecimiento de condiciones adicionales para la obtención del crédito. La fijación de montos de préstamos por tipo y actividad resulta la mayoría de las veces en una insuficiencia de fondos para llevar a cabo las actividades planificadas. El establecimiento de condiciones más duras para la tramitación de los préstamos incrementan los costos de transacción. Estos costos pueden constituirse en una barrera para el acceso al crédito formal de prestatarios sobre todo pequefios.

Con la ayuda de un gráfico se puede visualizar mejor la situación que

Figura 2. Prestatario con racionamiento en el monto de préstamo.

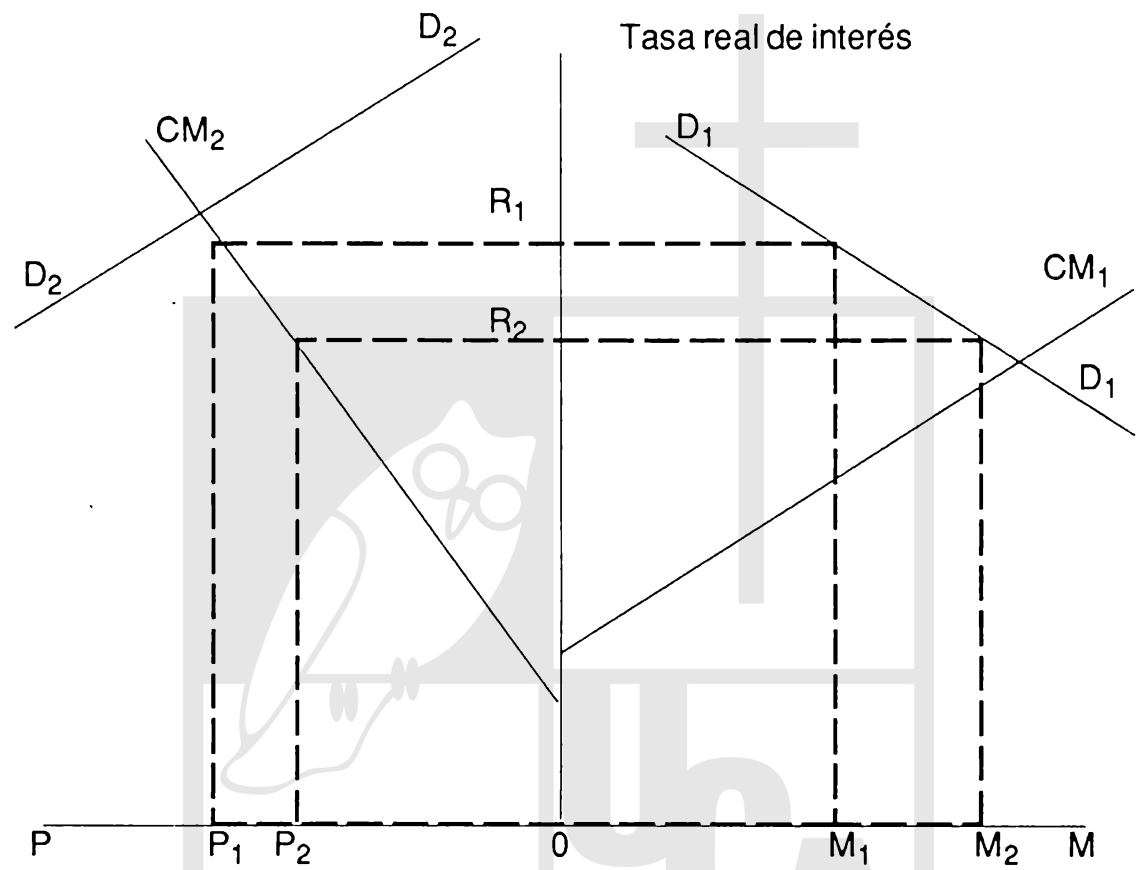

confrontan los prestatarios cuando se fijan las tasas de interés a niveles que no cubren los costos de los prestamistas.

Como se muestra en la Figura 2, a partir del origen se mide el tamaño del préstamo en unidades monetarias para el prestatario 1 y 2 . El prestatario 1 tienen la curva de demanda $D_{1} D_{1}$ y el prestatario 2 , la $D_{2} D_{2}$. Las curvas de demanda son funciones inversas de las tasas de interés real. se ha marcado para cada préstamo el costo marginal como una función creciente del tamaño del préstamo $\mathrm{CM}_{1}$ y $\mathrm{CM}_{2}$.

Si la tasa de interés se fija en $r_{1}$, el prestatario 1 recibe el monto solicitado de préstamo al nivel $\mathrm{OM}_{1}$, pués el nivel de la tasa de interés 
está por sobre la curva de su costo marginal. En cambio el prestatario 2 recibe un préstamo igual a $O P_{1}$ que es inferior a la cantidad demandada. Si la tasa de interés se fija a un nivel inferior $r_{2}$, el prestatario 1 recibe un monto adicional de $\mathrm{OM}_{1}$ a $\mathrm{OM}_{2}$. Por otro lado, el prestatario 2, reduce el monto recibido de $\mathrm{OP}, \mathrm{a} \mathrm{OP}_{2}$.

De lo anterior se puede concluir que cuanto más baja la tasa de interés existe mayor concentración de los préstamos en manos de individuos o empresas cuyos préstamos tienen menores costos; y además tienen ya un patrimonio considerable. Los pequeños empresarios, individuos pobres se ven racionados en los montos o marginados del mercado. ${ }^{8}$

\section{Financiamiento al sector agrario reformado salvadoreño}

\section{Antecedentes}

Las reformas emprendidas en El Salvador después de la Revolución de 1979 tuvieron entre otras la finalidad de consolidar una nueva estructura de tenencia de la tierra a través de la implementación de las Fases I y III de la Reforma Agraria y simultaneamente garantizar el éxito de esa reforma mediante la nacionalización de las instituciones de crédito y de las asociaciones de ahorro y préstamo. Se implementaron dos fases de la Reforma Agraria: la Fase I y la Fase III.

Fase I. Esta fase se estableció el 6 de marzo de 1980, mediante el Decreto Ley No. 153. Fueron sujetas de expropiación propiedades que excedian las 500 hectáreas. Además de la tierra se expropiaron la maquinaria y el equipo, el ganado y las otras instalaciones y construccioné para ser consolidadas en una propiedad colectiva. Al 31 de diciembre de 1987, se afectaron 469 propiedades beneficiando directamente a unas 31,359 familias.

Fase III. Esta fase se estableció en abril de 1980, mediante el Decreto 207. Esta fase dió la oportuniad a los campesinos que rentaban la tierra o trabajaban como aparceros de comprar una parcela hasta por un máximo de siete hectáreas. Bajo esta fase, el gobierno no expropió la tierra a no ser que los interesados iniciaran el reclamo o acción corespondiente. Al 31 diciembre de 1987, se beneficiaron 56,188 familias.

La Ley de Nacionalización de las Instituciones de Crédito y de las Asociaciones de Ahorro y Préstamo, Decreto No. 158, de la Junta Revolucionaria de Gobierno, entró en vigor en marzo de 1980. La banca nacionalizada, el Banco Hipotecario (BH), el Banco de Fomento Agropecuario (BFA), la Federación de Cajas de Crédito (FEDECREDITO) y el Instituto Nacional del Café (INCAFE) asumieron la obligación de prestar servicios financieros a un número determinado de cooperativas de la Fase $\mathrm{I}$. 
La experiencia de las instituciones como financiadores de los clientes surgidos del nuevo orden social fue desigual. Muchas de las inicialmente asignadas a FEDECREDITO e INCAFE fueron reasignadas al sistema bancario. Aquellas que la banca comercial dejó de considerarlas sujetos de crédito fueron listadas en el BFA. Al 30 de junio de 1987, fueron 266 las cooperativas que estaban formalmente asignadas a la banca comercial y al BFA. De las 266, 132 corespondían al BFA y 134 a los bancos comerciales. La asignación de una cooperativa a una institución financiera obliga a la última a prestar servicios financieros. Sin embargo, pueden haber razones de peso, tales como una carga excesiva de deuda, problemas administrativos serios en la cooperativa, o abandono de las tierras por parte de los cooperativistas que justificarían a la IF suspender la provisión de servicios.

\section{Participación de las cooperativas en el financiamiento}

Según datos proporcionados por el sistema bancario salvadoreño, al 30 de junio de 1986 la cartera agrícola consolidada totalizó $₫ 1,471.3$ millones. De estos, $₫ 269.6$ millones, o sea, el $18.3 \%$ estaban colocados en las cooperativas. El Banco Salvadoreño tenía el $280 \%$ de su cartera agrícola en las cooperativas, seguido por el BFA con $25.8 \%$, el Banco Mercantil $20.5 \%$, Banco de Comercio el $18 \%$ y el Banco Financiero el $15.1 \%$. Los demás bancos tuvieron entre $8.3 \%$ y $12.6 \%$ de su cartera agrícola en las cooperativas.

Al 30 de junio de 1987, la participación relativa aumentó ligeramente a $18.6 \% \cdot 9$

En la cartera de los bancos se contabilizan los saldos vigentes o en mora de cooperativas que inicialmente estuvieron financiadas por ellos aunque al presente estén con otro banco o no existan más como grupo cooperativo.

\section{Sistema de entrega de crédito}

Para la concesión de préstamos agropecuarios, el sistema bancario comercial depende mayormente de las líneas de redescuento del Banco Central de Reserva de El Salvador (BCR). Por ejemplo, del crédito de producción otorgado de enero a diciembre de 1987 , el $60.6 \%$ correspondió a fondos del BCR y sólo el $39.4 \%$ a fondos propios de los bancos. En el caso del crédito a las cooperativas, el $90.1 \%$ del credito otorgado en 1987 se dió con fondos del BCR. Esto significa que además de los trámites en el banco, las cooperativas deben casi necesariamente seguir el trámite en el BCR.

Las tasas de interés tanto pasivas como activas son fijadas por la Junta Monetaria. Las tasas vigenteas a partir del 1 de junio de 1987 para el 
crédito de producción varían entre el $13 \%$ y $15 \%$ anual. Las tasas para crédito de inversión varian de acuerdo al orígen de los fondos, pero en ningún caso sobrepasa el $17 \%$ anual. Tomando en consideración el nivel de inflación que se reporta para 1987 de 24\%, estas son negativas. Este hecho genera un exceso de demanda, que se evidencia en el flujo de solicitudes a los bancos y de estos BCR. Ante esta situación, parece lógico suponer que existan mecanismos diferentes al precio para liquidar este mercado.

El procedimiento para la aprobación de créditos de producción parece simple cuando los prestatarios pueden cumplir con los requerimientos exigidos. Sin embargo, el sistema no funciona para el otorgamiento de préstamos pequefios y se vuelve complejo para la tramitación de préstamos de inversión de mediano o largo plazo. El préstamo de inversión de mediano o largo plazo. El préstamo de inversión, independientemente del monto requiere un estudio de factibilidad. Este estudio es analizado tanto en el banco comercial como en el banco intermediario. Por ejemplo, algunos préstamos otorgados bajo la línea 519-0307 tardaron hasta cinco meses desde su presentación al banco hasta su aprobación en BCR.

El mecanismo complejo y lento incrementa los costos de transacción tanto del usuario del préstamo como el de la institución financiera. En el caso de clientes que tienen posibilidad de acudir a más de una fuente de financiamiento, las demoras en la aprobación de crédito y desembolso se resuelven fácilmente, pero en el caso de las cooperativas de la Fase I que dependen de un solo financiador, la demora en la aprobación y desembolso de sus fondos pueden resultar en pérdidas irrecuperables.

\section{Costos de transacción}

No existe mucha documentación sobre los costos de transacción del usuario del crédito aunque se han hecho intentos de medir cuánto cuesta a las intituciones financieras efectuar un préstamo. Recientemente, se elaboró un estudio de caso sobre costos de transacción de usuarios de préstamos agropecuarios del período 1985-1986 y 19861987 para las agencias de Sonsonate y San Miguel del Banco Hipotecario. Los datos obtenidos a través de este estudio apoyan las hipótesis de que los costos de transacción son significativos sobre todo para préstamos pequeños. ${ }^{10}$

Por ejemplo para un préstamo de $₫ 15,000.00$ se gastó en su tramitación $₫ 1,783.69$. El costo financiero de ese mismo préstamo fue de $\$ 2.250 .00$, resultando un costo total de $\$ 4,033.69$. Por lo tanto, los costos de transacción constituyeron el $11.89 \%$ del monto de préstamo cuando la tasa de interés nominal se había fijado en $15 \%$ anual. En este caso el prestatario pagó una tasa efectiva del $26.89 \%$. 
Se plantea también el caso de un préstamo de $₫ 7,650,900$. El costo de transacción del préstamo totalizó $\$ 21,040.40$ y el costo financiero $\varnothing$ $1,300,653$. El costo de transacción representó $0.28 \%$ del monto de préstamo y $1.64 \%$ del costo financiero.

En el estudio se plantea la hipótesis de que los costos de transacción son una función del tamaño del préstamo, el plazo. La garantía, nivel de educación, distancia del domicilio del agricultor al banco, la tasa nominal de interés y el tiempo de relación del cliente con el banco. Con los datos obtenidos a través de una encuesta aplicada a 67 prestatarios de las agencias indicadas se concluye que existe una alta correlación entre el nivel de los costos de transacción y las variables anteriores.

A la pregunta que los encuestadores formularon sobre el tiempo que tardó el Banco en efectuar el primer desembolso, $50 \%$ respondió que tardó más de dos meses, el $30 \%$ más de un mes y medio y el $20 \%$ entre 15 días y un mes. El número menor de visitas reportado por los prestatarios entrevistados fue de 14 veces y algunos indicaron que tuvieron que ir hasta 30 veces. Lo anterior puede ser una indicación de que las IFs de El Salvador no están tomando en consideración los gastos en que incurren los prestatarios al tramitar sus préstamos.

En el caso de las cooperativas de la Fase I se debe afiadir un elemento adicional de demora para la contratación de sus préstamos, que es la obtención del aval del Intituto Salvadoreño de Transformación Agraria (ISTA). No existe una documentación sobre los costos en que incurren las cooperativas al tramitar sus préstamos. La hipótesis es que estos son comparativamente más altos que los de los clientes tradicionales. Las continuas visitas de los grupos de directores acompanados del gerente a los bancos significan gastos en efetivo y costo de oportunidad del tiempo utilizado en tratar de acelerar sus trámites. Asi mismo se reportan frecuentemente pérdidas de cosechas atribuíbles a desembolsos no oportunos.

\section{Comportamiento de las Instituciones Financieras}

Las instituciones financieras salvadorefias deben sujetarse a lo establecido en la Ley de Instituciones de Crédito y Organizaciones Auxiliares (LICOA) disposiciones de la Junta Monetaria y regulaciones del BCR. Los objetivos que deben lograr están sefialadas en alguna manera en las propias leyes. Implíçitamente se indica que deben optimizar su rentabilidad dadas las condicones expresadas en las disposiciones indicadas.

Lo anterior significa que deben decidir: (1) sobre el manejo de los activos y pasivos, (2) manejo de riesgo en sus decisiones para obtener una óptima rentabilidad. 
Con relación a los activos, estos deben estar colocados entre cartera y reservas de acuerdo a lo establecido en LICOA sobre el fondo operativo, la Resolución 14/87 de la Junta Monetaria sobre la composición de cartera y mantener coeficientes especiales de encaje. 11

Con relación al manejo del riesgo, la ley y regulaciones previenen a las instituciones de correr riesgos innecesarios.

Dentro de las limitaciones sefialadas por la Ley y las disposiciones adicionales y sus propias limitaciones físicas, las IFs tienen oportunidad de mantener una variedad de activos pudiendo escoger de esa variedad una composición de cartera eficiente. Esto significa que tienen la posibilidad de seleccionar a sus clientes porque a las tasas de interés vigentes existe un exceso de demanda por crédito. Dada esta situación las IFs están en posición de seleccionar a su clientela marginando a los clientes que puedan ser considerados un alto riesgo. Por lo tanto, su conducta es probable que sea similar a las del monopolista de planta múltiple que discrimina a los prestatarios utilizando mecanismos de racionamiento vía no precio.

En el caso de las cooperativas, el hecho de haberles asignado una institución financiera para atenderlas no garantiza que ellas tienen asegurado el crédito. Este supuesto fue verdadero sólo inicialmente. Pero, al presente, las instituciones financieras tienen un récord sobre ellas y posiblemente muchas ya no son sujetos de crédito para ninguna institución financiera. Existe una clasificación al 30 de septiembre de 1987, para 334 cooperativas de la Fase I. De las 334,87 se supone que no tienen más acceso al crédito, porque de esas, 32 se consideraron abandonadas 37 sin clasificación y 18 calificadas como D. De las restantes 247,117 tuvieron la clasificación C, 65, B y otras 65 , A. Las calificaciones anteriores estaban basadas en criterios de oganización y manejo gerencial, solidez financiera, logros sociales y mayor o menor grado de cohesión de los socios de la cooperativa.

\section{Conducta de los prestatarios}

Se supone que las empresas e individuos destinan los recursos obtenidos del crédito y los recursos propios en actividades de las cuales esperan obtener una óptima rentabilidad. Por lo tanto, ellos tienen una lista de prioridades de las inversiones basada en las tasas esperadas de retorno. Si tienen posibilidades de obtener fondos adicionales seguirán invirtiendo en usos cada vez menos rentables. Cuando tienen posibilidad de obtener un crédito cuya tasa de interés es subsidiada estarán incentivados a llevar a cabo actividades cuyas tasas internas de retomo son menores y probabilidades de éxito menor.

Las cooperativas de la Fase I, como cualquier otra firma, se supone 
que deverian seguir el mismo patron de comportamiento, o sea, optimizar los retornos esperados. Sin embargo, existen evidencias, de que un buen número de ellas persiguen objetivos tales como optimizar el nivel de salario de los socios y en algunos casos la de incrementar las horas disponibles de trabajo.

El hecho de que traten de pagar un mejor salario a los socios y generar trabajo no necesariamente está refída con la eficiencia, pero si no se toman en cuenta principios de eficiencia en el costo, los ingresos podrían no cubrir los gastos.

\section{Racionamiento}

La existencia de las múltiples líneas de redescuento cada una con condiciones sobre montos, plazos, tasas de interés, garantías y sujetos de crédito evidencia de por sí algún tipo de racionamiento. Por ejemplo, un productor de café debe justificar el monto del crédito al que puede aplicar en base a un promedio de las tres mejores cosechas de los últimos cinco afnos. Esa producción promedio en quintales se debe multiplicar por el monto de $\$ 200.00$. El resultado es la base del monto de préstamo.

Los $₫ 200.00$ están divididos en $₫ 100.25$ para recolección $₫ 46.50$ para insumos varios, $₫ 51.00$ para mano de obra y $\$ 3.25$ para administración. Hay varios supuestos implícitos en la aplicación de este sistema. Primero, se supone que el prestatario tratará de justificar el monto mayor posible de préstamo, por lo tanto es necesario establecer un monto máximo basado en las producciones de los anos anteriores. Segundo, el monto de $\$ 200.00$ está basado en el supuesto de que la producción de un quintal tiene un costo promedio de $\$ 200.00$. Tercero, implícitamente se acepta que una tecnología mejorada tiene un mayor costo. Finalmente, se supone que el $100 \%$ de los fondos obtenidos en el crédito serán utilizados en el cultivo.

El primer supuesto es verdadero en la media en que las tasas de interés sean negativas en términos reales. El segundo y tercer supuesto son sólo verdaderos parcialmente. Existen variables que no necesariamente están relacionadas con la tecnología y que sin embargo pueden ser factores determinantes en el volumen de producción. Estos factores incluyen los desastres naturales que no afectan a todos los agricultores por igual y algunas plagas se presentan aisladamente. El cuarto supuesto tampoco es verdadero, porque siendo el dinero fungible el agricultor destina los fondos obtenidos en los usos de los cuales espera la mejor rentabilidad.

Con la fijación de montos de préstamos basado en los promedios de producción, algunos prestatarios recibirán más de lo que realmente nece- 
sitan y otros menos. Pero todos quisieran recibir más, aunque en la práctica, sean pocas los que realmente utilicen todo el préstamo obtenido en el cultivo para el cual se obtuvo el préstamo.

\section{Concentración de crédito}

Los datos disponibles muestran que son pocos los agricultores que reciben crédito y que los montos promedios son relativamente. El Cuadro 1 proporciona información sobre el número de préstamos de avío otorgados de enero a diciembre de 1987 por la banca comercial con fondos del BCR y fondos propios de los bancos.

Como se muestra en el Cuadro sólo se otorgaron 2,620 créditos de avío por un monto de $₫ 587.9$ millones siendo el promedio del préstamo de $\$ 200.000$ : Esto significa que probablemtne menos de 2,500 agricultores recibieron crédito de avio de la banca comercial, pués en muchos casos más de un crédito se concedió a la misma persona o empresa.

En el caso de los pequeños agricultores beneficiarios del Decreto 207, su marginación del financiamiento es evidente. Al 31 de diciembre de 1987, la banca nacionalizada atendió a menos de 2,000 familias, el BFA reporta en la cartera de esa fecha 13,010 préstamos. Se supone que el número de prestatarios es menor, porque más de un prestatario puede haber obtenido más de un préstamo. El Banco Hipotecario no ha tenido nunca una experiencia con este tipo de clientela.

En el financiamiento al sector, se puede observar un crecimiento en la cartera debido a la mora y refinanciamiento. Los fondos prestables cada vez más reducidos se van colocando sólo en clientes cuyo récord crediticio es óptimo. Por otro lado, sucede también que la capacidad de endeudamiento de muchos prestatarios ha llegado al máximo.

Para apoyar la afirmación anterior, se incluye el Cuadro 2 como Anexo I de esta exposición con la Cartera del Sector Agrario Reformado, desglosada por banco y por tipo de préstamo: (1) producción (avio). (2) inversión y (3) cartera refinanciada, al 31 de diciembre de 1987.

Como se muestra en el Cuadro, $34.8 \%$ de la cartera de la banca comercial y el BFA estuvo refinanciada. El Banco Hipotecario, el Banco Agrícola Comercial, el Banco Salvadoreño, el Banco de Crédito Popular, el Banco de Desarrollo e Inversión presentaron un alto porcentaje de su cartera con problemas de refinanciamiento. El Banco Financiero, Banco Mercantil, el Banco Capitalizador y el Banco Cuscatlán mostraron una cartera menos problemática.

Por el monto de la cartera refinanciada, el BFA, el Banco Hipotecario, el Banco Salvadoreño y el Banco Agrícola Comercial tuvieron comprometidas sumas importantes en cartera refinanciada. 
Si bien no se pudo obtener datos de refinanciamiento para toda la cartera agropecuaria probablemente el porcentaje de la cartera refinanciada del sector no reformado es por lo menos igual al del reformado.

Las causas que dificultan la recuperación de la cartera son múltiples. Concretamente, en el caso de las cooperativas, se sefialan la falta de cohesión entre los socios, administración deficiente, gerentes y directores carentes de honestidad, desastres naturales, política inadecuada, fluctuación en los precios de los mercados internacionales, tecnología inapropiada, deficientes canales de comercialización, la guerra civil, etc.

Se reconoce generalmente que existen esos problemas, pero no se ataca el mal en la base sino que se espera que el crédito subsidiado compense parcial o totalmente los perjuicios emergentes de las condiciones anteriormente senaladas.

\section{Conclusiones}

En el Salvador, al igual que en la mayoría de bs países de bajos ingresos, se ha dirigido el crédito a objetivos específicos mediante la canalización de fondos a líneas de redescuento del BCR. Estos recursos han sido propios del BCR o de instituciones de ayuda externa. Cada linea ha sido establecida con sus propias condiciones, 0 sea, ha tenido un sistema de entrega de crédito particular. Los costos de transacción asociados a los sistemas de entrega de crédito parecen altos, tal como se documenta en un estudio de caso realizado para las agencias de Sonsonate y San Miguel del Banco Hipotecario.

Las tasas reales de intéres de los préstamos en general y más aún de los préstamos agropecuarios han resultado negativas con el incremento de las tasas de inflación de los últimos tres años. Por lo tanto, se ha generado un exceso de demanda. Dada la situación de exceso de demanda y la voluntad política de mantener las tasas de interés a los niveles anteriores a la inflación, las intituciones financieras tienen alternativas de selección de clientela, ajustando su conducta a la de un monopolista de múltiple planta y con discriminación de precio. Pero, como cada clase de préstamo tiene un costo diferente y no pueden variar la tasa de interés, trasladan parte de sus costos de transacción al prestatario. De este modo, marginan del mercado a clientes considerados de mayor riesgo y a otros que podrian generarles mayores costos.

Como quiera que aproximadamente un $61 \%$ de los fondos de préstamos agropecuarios del sistema bancario comercial viene de las líneas de redescuento del BCR, los prestatarios deben justificar su préstamo en ambas instituciones. En el caso de las cooperativas de la Fase I un $90 \%$ de los préstamos de 1987 se otorgaron con fondos del BCR y además sus préstamos deben ser autorizados por la Junta Directiva del BCR inde- 
pendientemente del monto. Otro elemento de demora en la tramitación constituye el aval de ISTA, pues mientras no exista el aval no pueden legalizar su préstamo.

Dado que las instituciones financieras deben lograr objetivos de rentabilidad por el mismo hecho que deben responder a los depositantes que confían en ellas sus fondos y además ajustar su conducta a las disposiciones legales y directivas de la Junta Monetaria y el BCR, el hecho de asignarles un determinado número de clientes fortalece su poder monopólico. Si bien inicialmente podrían arriesgar préstamos con todas las cooperativas, al presente las tienen ya clasificadas como sujetos o no sujetos de crédito.

Visto del lado de las cooperativas, la asignación de éstas a una institución crediticia determinada crea falsas expectativas de obtener un servicio adecuado. Sin embargo, si por alguna razón no obtienen financiamiento no tienen otra alternativa en el mercado formal ni informal, pues es dudoso que algún individuo o empresa brinde sus recursos prestables a las cooperativas de la Fase I. Para las cooperativas de la clase D o abandonadas no parece existir una posibilidad de obtención de recursos financieros adicionales.

En otro extremo las 65 que tienen clasificación "A" podrían ser clientes de cualquier institución financiera. Estas probablemente son penalizadas al asignar un solo organismo financiador.

Las premisas en las que se basa la asignación de cuotas no parecen verdaderas, pues el tomar promedios de costos, promedios de rendimientos está necesariamente concediendo mayor o menor monto del que realmente requieren los clientes. Como por otro lado parece verdadera la suposición de que todos quisieran tener mayor monto de préstamo, a las tasa vigentes, es probable que los que más obtengan sean los que menos requieren.

Los fondos para préstamos nuevos parece que se reducen cada vez mas sobre todo en términos reales y la cartera de la instituciones se incrementa a través de préstamos morosos y del refinanciamiento. Este hecho agrava el racionamiento y hace que menos pequefios prestatarios y menor número de cooperativas obtengan los préstamos solicitados. Poner más fondos a disposición de las líneas de redescuento no resuelve totalmente el problema, porque los que no son sujetos de crédito no se volverían tales, sólo por la disponibilidad de fondos incrementados.

Tanto en el sector agropecuario tradicional como reformado se espera mucho del financiamiento. Sin embargo, el crédito por sí solo no va a producir resultados positivos en presencia de otros factores, tales como nivel de precios que no guarda relación con los costos de producción, falta de tecnología, gerencia y administración deficientes, deshonestidad 
de directores en el manejo de los recursos de las cooperativas, falta de canales de comercialización adecuados, falta de infraestructura para el transporte de productos, etc.

El panorama del financiamiento al sector y el funcionamiento de los mercados financieros rurales en general de El Salvador parece confrontrar los problemas típicos de los mercados financieros rurales de otros paises. Las soluciones adecuadas probablemente no consisten en medidas tradicionales de nuevas líneas, nuevos incentivos de mayor spread a instituciones que arriesguen más con prestatarios problemáticos, sino en buscar las causas mismas de los problemas. El alto porcentaje de préstamos en mora y en refinanciamiento además de reducir la oferta marginan del mercado a los más necesitados.

Notas

1. Admas, Dale W., Graham, Douglas H., and Von Pischke, J. D., eds., Underminig Rural Developmet with Cheap Credit, Boulder Colorado: Westview Press, 1984.

2. Mucho énfasis se ha puesto en los ultimos años en la investigación del comportamiento de los mercados financieros. Fruto de estas investigaciones no solamente ha resultado en publicaciones de libros y textos sobre crédito con una nueva filosofía a la doctrina tradicional, sino que también se ha logrado introducir algunas innovaciones en el diseño de los nuevos programas de crédito. Lógicamente el cambio parece difícil. A.I.D. y el Banco Mundial han liderizado en el apoyo a las investigaciones en los diferentes continentes. En la actualidad muchas de las políticas sobre crédito se basan en las teorlas recientemente difundidas. Este nuevo punto de vista se puede encontrar en varias publicaciones. Por ejemplo, en el libro: Rural financial Markets in Developing Countrles, publicado por el Instituto de Desarrollo Económico del Banco Mundial y editado por J.D. Von Pischke, Dale W, Adams, y Gordon Donald. La Universidad del Estado de Ohio tiene en existencia un conjunto de publicaciones en español, con los resultados de investigaciones recientes.

3. La tasa de interés real se define con la tasa nominal, o sea, la que aparece en el contrato, ajustado por un cambio en el nivel de precios. Esta tasa es igual a ( (1+i)/ $(1+p)-1)$, donde i es la tasa de interés nominal, $p$ es el cambio en los precios durante un año.

4. Claudio González-Vega, "Cheap Agricultural Credit: Redistribution in Reverse", en Dale W. Adams, Douglas H. Graham y J. D. Von Pischke, eds., op. cit.

5. Claudio González-Vega, "Arguments for Interest Rate Reform" en J. D. Von Pischke, Dale W. Adams, Gordon Donald, eds. Rural Financial Markets in Developing Countrles. The Hopkins University Press, 1983.

6. Jerry R. Ladman, "Loan-Transactions Costs, Credit Rationig, and Market Structure; the Case of Bolivia", en Dale W. Admas, Douglas H. Graham y J. D. Von Pischke, ods., op. clt.

7. Diversas tesis se han elaborado últimamente sobre la materia. En El Salvador se acaba de defender una tesis titulada "Estudio de Costos de Transacción de Préstamos Agropecuarios de El Salvador (caso Agencias Sonsonate y San Miguel del Banco Hipotecario de El Salvador). Esta tesis fue presentada para optar el grado de licenciatura en economía por Ana Maritza Fernández Soto, Delmy Violeta Segovia de Girón y Remberto Edgardo Rivera. 
8. El modelo para explicar el racionamiento ha sido planteado anteriormente por el Doctor Claudio González-Vega en el artículo "Credit-Rationing Behavior of Agricultural Lenders: The Iron Side Law of Interest Rate Restrictions", en Dale W. Adams, Douglas A. Graham y J. D. Von Pischke, eds. op. cit.

9. Un anális isde la Cartera Agrícola del sistema bancario comercial salvadoreño al 30 de junio de 1987, su puede encontrar en "Lending to the Reform Sector, as of June 30 , 1987", por José Isaac Torrico, documento de trabajo no publicado.

10. Tesis para optar licenciatura en economia presentada por Ana Maritza Fernández Soto, Delmy Violeta Segovia de Girón y Remberto Edgardo Rivera, antes citada.

11. El Artículo 43 de LICOA establece que las instituciones de crédito deben mantener un fondo constituido por capital y reservas que por lo menos sea el $8 \%$ de sus colocaciones en crédito y el $40 \%$ de sus inversiones que consistan en títulos o acciones en sociedades anónimas. La composición de la cartera debe sujetarse a la Resolución 14/87 del 9 de septiembre de 1987 de la Junta Monetaria que estipula que el $26.1 \%$ de la cartera debe ser agropecuaria, el $33.1 \%$ estar en la industria manufacturera, el $11 \%$ estar en construcción, el 14 . $7 \%$, en comercio y el $5.4 \%$ y $9.7 \%$ en servicios y otros servicios, respectivamente. Asimismo, de los recursos captados del público, el $15 \%$ deben estar colocados en empresas que tengan un activo de $\$ 750,000$ y por lo menos el $2 \%$ en préstamos con activos de $₫ 100.000$ o menores.

\section{Cuadro 1. Créditos de avío otorgados por el Sistema Bancario Comercial Salvadoreño Enero - Diciembre, 1987} (monto c millones)

\begin{tabular}{|c|c|c|c|c|c|c|c|c|c|}
\hline \multirow{2}{*}{$\begin{array}{l}\text { Fuente } \\
\text { de } \\
\text { Recursos }\end{array}$} & \multicolumn{3}{|c|}{ Sector reformado } & \multicolumn{4}{|c|}{ Sector no reformado } & \multicolumn{2}{|c|}{ Total } \\
\hline & $\begin{array}{l}\text { Núme. } \\
\text { Crédit. }\end{array}$ & Mon. & $\begin{array}{l}\text { Monto } \\
\text { Prom. }\end{array}$ & $\begin{array}{l}\text { Núme. } \\
\text { Crédit. }\end{array}$ & Mon. & $\begin{array}{l}\text { Monto } \\
\text { Prom. }\end{array}$ & $\begin{array}{l}\text { Núme. } \\
\text { Crédit. }\end{array}$ & Mon. & $\begin{array}{l}\text { Monto } \\
\text { Prom. }\end{array}$ \\
\hline \multirow{2}{*}{$\begin{array}{l}\text { Rec. BCR } \\
\text { Recursos } \\
\text { Propios } \\
\end{array}$} & 420 & 92.2 & 0.22 & 1,084 & 264.2 & 0.24 & 1,504 & 356.4 & 0.24 \\
\hline & 562 & 29.1 & 0.05 & 554 & 202.4 & 0.37 & 1,116 & 231.5 & 0.21 \\
\hline Total & 982 & 121.3 & 0.12 & 1,638 & 466.6 & 0.28 & 2,620 & 587.9 & 0.22 \\
\hline
\end{tabular}

Fuente: Basado en información proporcionada por el Sistema Bancario.

Cuadro 2 cartera de las cooperativas del sector reformado al 31 de diciembre de 1987 por Banco (Millones de Colones)

\begin{tabular}{|c|c|c|c|c|c|c|c|c|}
\hline Banco & $\begin{array}{l}\text { Crédito } \\
\text { de Pro- } \\
\text { ducción }\end{array}$ & n & $\begin{array}{l}\text { Crédito } \\
\text { de In- } \\
\text { versión }\end{array}$ & $\%$ & $\begin{array}{l}\text { Crédito } \\
\text { Refi- } \\
\text { nanciado }\end{array}$ & $\%$ & Total & $\%$ \\
\hline \multirow[t]{2}{*}{$\begin{array}{l}\text { Bco. Agricola Comercial } \\
\text { Bco. Capitalizador } \\
\text { Bco. de Comercio } \\
\text { Bco. de Crédito Popular } \\
\text { Bco. Cuscatlán } \\
\text { Bco de Desarrollo e Inv. } \\
\text { Bco. Financiero } \\
\text { Bco. Hipotecario } \\
\text { Bco. Mercantil } \\
\text { Bco. Salvadoreño } \\
\text { Bco. de Fomento } \\
\text { Agropecuario }\end{array}$} & $\begin{array}{r}9.3 \\
7.0 \\
5.9 \\
9.8 \\
21.5 \\
2.7 \\
1.7 \\
33.2 \\
5.3 \\
12.4\end{array}$ & $\begin{array}{l}35.2 \\
59.3 \\
39.9 \\
55.4 \\
61.1 \\
58.7 \\
77.3 \\
44.9 \\
79.1 \\
34.6\end{array}$ & $\begin{array}{l}4.8 \\
4.3 \\
2.8 \\
1.4 \\
8.8 \\
0.4 \\
0.5 \\
2.9 \\
1.4 \\
8.3\end{array}$ & $\begin{array}{r}18.2 \\
36.5 \\
18.9 \\
7.9 \\
25.0 \\
8.7 \\
22.7 \\
3.9 \\
20.9 \\
23.2\end{array}$ & $\begin{array}{r}12.3 \\
0.5 \\
6.1 \\
6.5 \\
4.9 \\
1.5 \\
-. \overline{-} \\
37.8 \\
15.1\end{array}$ & $\begin{array}{r}46.6 \\
4.2 \\
-41.2 \\
36.7 \\
13.9 \\
32.6 \\
51.2 \\
-.- \\
42.2\end{array}$ & $\begin{array}{r}26.4 \\
11.8 \\
14.8 \\
17.7 \\
35.2 \\
4.6 \\
2.2 \\
73.9 \\
6.7 \\
35.8\end{array}$ & $\begin{array}{l}100 \\
100 \\
100 \\
100 \\
100 \\
100 \\
100 \\
100 \\
100 \\
100\end{array}$ \\
\hline & 69.4 & 35.7 & 62.4 & 32.1 & 62.7 & 32.2 & 194.5 & 100 \\
\hline Total & 178.2 & 42.1 & 98.0 & 23.1 & 147.4 & 34.8 & 423.6 & 100 \\
\hline
\end{tabular}

Fuente: Basada en información proporcionada por las instituciones financieras. 